\title{
Construction Design, Modelling, and Parameter Computation Outer Rotor Induction Motor
}

\author{
Eka Iskandar \\ Department of Electrical Engineering \\ Institut Teknologi Sepuluh Nopember \\ Surabaya, Indonesia \\ iskandar@elect-eng.its.ac.id \\ Yusuf Bilfaqih \\ Department of Electrical Engineering \\ Institut Teknologi Sepuluh Nopember \\ Surabaya, Indonesia \\ bilfaqih@ee.its.ac.id
}

\author{
Rusdhianto Effendi Abdul Kadir \\ Department of Electrical Engineering \\ Institut Teknologi Sepuluh Nopember \\ Surabaya, Indonesia \\ ditto@ee.its.ac.id
}

Mohamad Abdul Hady

Department of Electrical Engineering

Institut Teknologi Sepuluh Nopember

Surabaya, Indonesia

hady@bme.its.ac.id

\author{
Ari Santoso \\ Department of Electrical Engineering \\ Institut Teknologi Sepuluh Nopember \\ Surabaya, Indonesia \\ santoso@ee.its.ac.id \\ Faizal Ramadhan Putra \\ Department of Electrical Engineering \\ Institut Teknologi Sepuluh Nopember \\ Surabaya, Indonesia \\ faizal.ramadhan16@mhs.ee.its.ac.id
}

\begin{abstract}
In this journal, we will discuss the construction design of an outer rotor induction motor that can be applied to an electric car that is installed inside the car's wheels. In designing a motor, it is necessary to pay attention to the motor parameters, both mechanical parameters, and electrical parameters. These parameters will be calculated using software and designed in such a way as to get the parameters that are as effective and efficient as possible for the use of electric cars. After obtaining the best design, a comparison of the simulation results with mathematical modeling will be seen. In this final project, we can get a design with an initial torque of $64 \mathrm{Nm}$ for a speed limit of $25 \mathrm{~km} /$ hour.
\end{abstract} rotor.

Keywords - construction, induction, in-wheel, motor, outer

\section{INTRODUCTION}

An environmentally friendly engine due to the absence of gas emissions is the advantage of using electricity as energy for the car. Electric motors are growing because they have advantages over combustion motors such as lower vibration, adjustable motor rotation speed, cleaner, and economical maintenance [1].

The electric machine used to convert electrical energy is an electric motor. Based on the energy source, electric motors are divided into two types, namely motors that use $\mathrm{AC}$ (Alternating Current) and those that use DC (Direct Current) electrical energy sources. Electric motors are also distinguished using magnets. Some electric motors use permanent magnets and some do not.

An induction motor is a type of electric motor that uses an AC (Alternating Current) source as its source. Simple construction, sturdy, relatively inexpensive, and easy maintenance are the reasons for the use of induction motors in various fields including the transportation sector. Without using permanent magnets, the induction motor has the advantage of easy maintenance as it has been because, if the permanent magnet is damaged of course you must dismantle and replace the motor.

Induction motor construction generally places the rotor on the inside of the stator. The rotor inside the stator cannot be used directly as the driving wheel but must be coupled with another driving wheel. The addition of a coupling to the motor makes the construction more complicated and adds to the value of power losses. However, when the rotor is outside the stator, the induction motor can be used directly as a driving wheel without a coupling so that the construction is simpler, and the power losses are reduced.

An outer rotor induction motor can be applied to electric cars. In electric cars, the use of an outer rotor induction motor has advantages compared to the inner rotor as previously described. However, the outer rotor induction motor has a small initial torque value because it does not use gears. Therefore, this study aims to find the design of an outer rotor induction motor that has the highest starting torque possible.

\section{METHODS}

\section{A. Basic Theory}

It is called an induction motor because the current that occurs in the rotor is caused by the voltage induced by the magnetic field coming from the stator. An induction motor is also called an asynchronous motor because the rotational speed of the stator rotating field is not the same as the rotational speed of the rotor.

An induction motor is a type of motor that is often used. In the industrial world, this motorbike is the prime mover for most machines. In the household sector, electric machines that use induction motors are often found, including fans, refrigerators, mixers, and so on. This motor is often used, especially in the industrial sector, because it has advantages over other types of motors including very simple and extremely rugged (almost unbreakable construction especially squirrel cage type), the cost is low and very reliable, sufficiently high efficiency, and minimum maintenance [2].

The construction of an induction motor consists of two main parts, namely the stationary part (static) and the rotating part. The stationary part is called the stator and the rotating part is called the rotor as shown in Figure 1. Both stator and rotor are formed from the electrical circuit which is usually made of copper or aluminium and the magnetic circuit which is usually made of laminated steel [3]. 


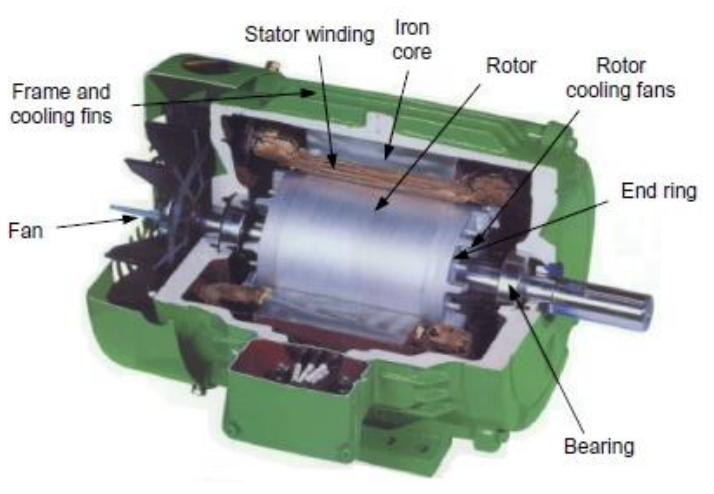

Fig. 1. Induction Motor Construction [4]

\section{1) Induction Motor Stator Construction}

The static (stationary) part of the motor called the stator is the part of the motor that serves as a place to adjust the rotating field on an induction motor. The stator has three main parts, namely the stator frame, the stator core, and the stator coil. The frame or stator shaft is the outermost part of the stator which functions as a support and stator protector, inside which there is a stator core and the stator coil. The stator core is made of laminated steel. The shape is hollow and patterned on the stator core is called the stator slot. This stator slot is used as a place for the stator coils. The stator coils are linked to the voltage source. The coil is wound in the stator gap by pattern and forming a few pairs of poles. The smaller the number of poles, the faster the rotational speed obtained but the smaller the torque. If the number of pairs of poles is greater, the rotational speed obtained will be slower but the torque will be greater.

The stator coil supplied with a three-phase voltage source will carry three-phase current. Three-phase current in the coil will produce a constant rotating flux or rotating field. This rotating field will cause an electromotive force on the rotor.

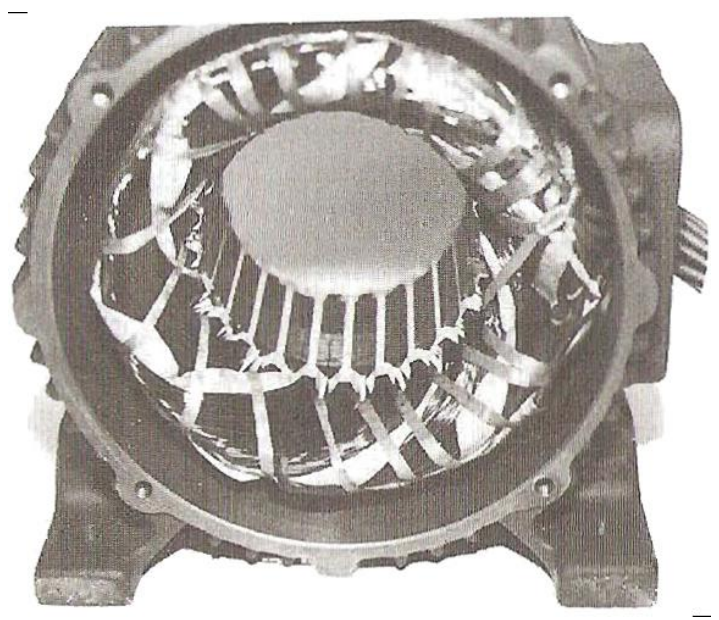

Fig. 2. Induction Motor Stator [5]

\section{2) Induction Motor Rotor Construction}

The rotating part (rotate) of the motor is called a rotor. Rotor consists of a stack of steel laminations with evenly spaced slots punched around the circumference. The surface is coated with an insulator (oxide layer) for preventing unwanted axial eddy currents [6]. This laminate is placed on the outside to receive flux from the rotating field.

The rotor conductors are not placed exactly parallel to the shaft but are skewed by one slot-pitch to reduce cogging torque, and the motor runs smoothly [4]. There are two types of rotors in induction motors according to their construction, namely the cage rotor and the winding rotor.

\section{a) Squirrel-Cage Rotor}

This type of induction motor has a coil in the form of several conductor rods arranged in a shape like a squirrel cage. construction of a squirrel cage rotor is simpler than a winding rotor. Squirrel cage rotors are cheaper than coil rotors. To limit the large starting current in this type of rotor, the voltage from the source must be reduced using a transformer or $y$-a switch. But the reduced current will result in a reduction in the coupling. The advantages of this type of motor are simple construction, low maintenance costs, and simple starting arrangements while the disadvantages of this type of motor are that speed variations can reduce efficiency, and speed decreases if the load increases, starting torque is lower slip.

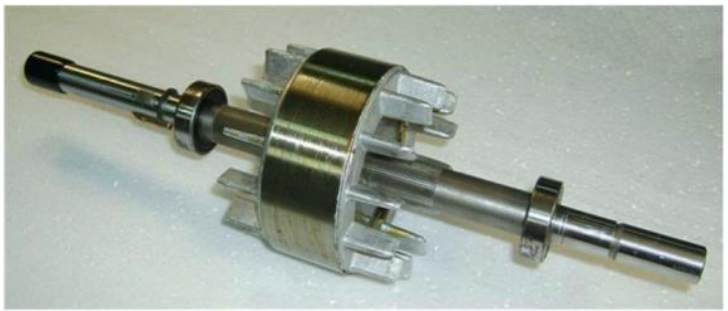

Fig. 3. Squirrel-Cage Rotor Induction Motor [4]

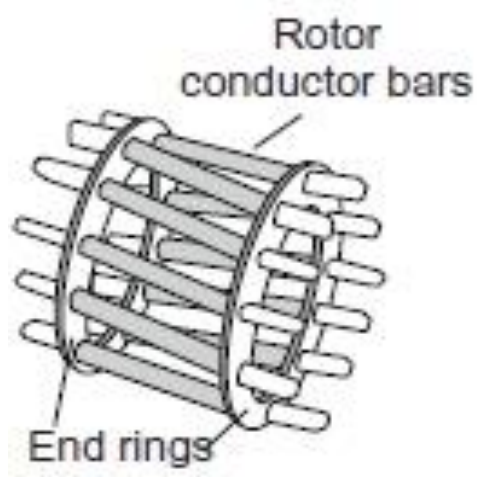

Fig. 4. Squirrel-Cage Rotor Induction Motor sketch [4]

\section{b) Wound Rotor}

Wound rotor type induction motor has a rotor with the same three-phase coil winding as a stator coil. The number of poles of the stator and rotor coils has the same amount. The rotor currents accessible at the stator brushes, where it can be examined and where extra resistance calls are inserted into the rotor circuit [4].

The addition of external resistance up to a certain price can create the coupling starting to reach its maximum price. A wound rotor type induction motor allows the addition (regulation) of external resistance. The outer resistance sets this to the rotor through the ring. Other than for resulting in a large initial coupling, the external resistance is required to limit the large initial status at start-up. Besides that, by varying the external resistance, the motor speed can be arranged. The advantages of this motor are high starting torque, low starting current, efficiency good under normal conditions while the drawback is more expensive than the squirrel cage rotor, it takes a lot of care and needs more complex automatic controls. 


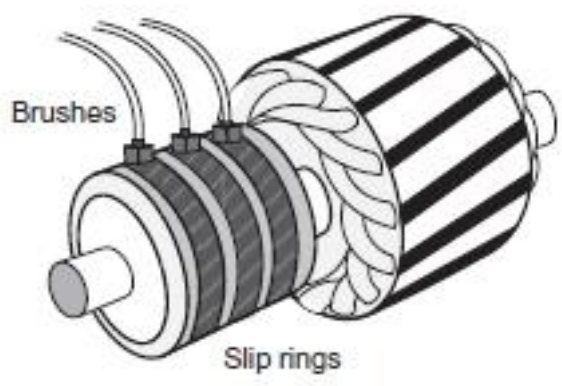

Fig. 5. Wound Rotor Induction Motor sketch [4]

\section{3) Induction Motor Working Principle}

As the name implies, an induction motor works by inducing a voltage. Initially, the stator coil consisting of threephase windings is supplied with a three-phase voltage source as shown in Figure 6.

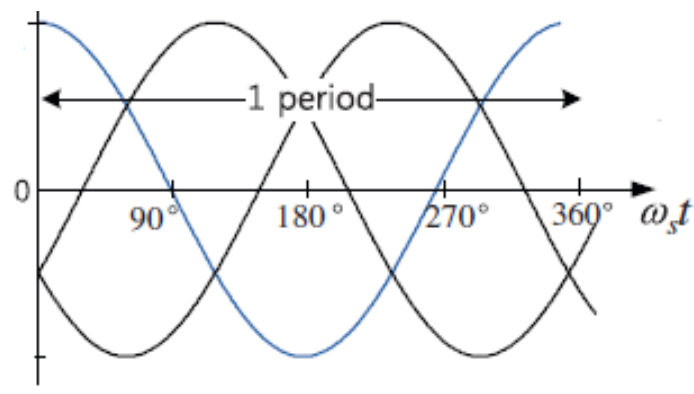

Fig. 6. Three-phase voltage [4]

The three-phase voltage supply to the stator coil creates a rotating field with synchronous speed, this synchronous speed is directly proportional to the source frequency and inversely proportional to the number of poles.

$$
\mathrm{n}_{\mathrm{s}}=\frac{120 \mathrm{fc}}{p}
$$

The rotating field cuts the conductor rod on the rotor so that the rotor is induced to cause an electric motive force. The existence of an electromotive force causes a voltage on the rotor or it can be called an induced voltage. Induction voltage formula:

$$
e_{\text {ind }}=(\mathrm{v} \times \mathrm{B}) . \mathrm{I}
$$

The circuit in the rotor is closed (closed loop). The presence of an induced voltage in the rotor which is a closed circuit will cause a current. The electric current in the rotor is within the range of the rotating field. The presence of current in the rotating field gives rise to magnetic torque which is called Lorenz force. Based on the Lenz law, the direction of the force tends to reduce the flux change itself, meaning that the rotor will rotate in the direction of the flux rotation or the direction of the rotating field. The rotating field or stator field reacts with the rotor field causing induced torque in the rotor which makes the rotor rotate. induction torque formula:

$$
T_{\text {ind }}=\mathrm{kB}_{R} \times \mathrm{B}_{S}
$$

The amount of torque produced by each phase is not the same at all times, because the amount of current in each phase varies with time. In Figure 2.6, the amount of current in each phase is different each time. The difference in current causes the torque to have different directions because it tends to lead to the phase that has the highest current. The torque resultant will rotate as the current changes in each phase and cause the rotor to rotate.

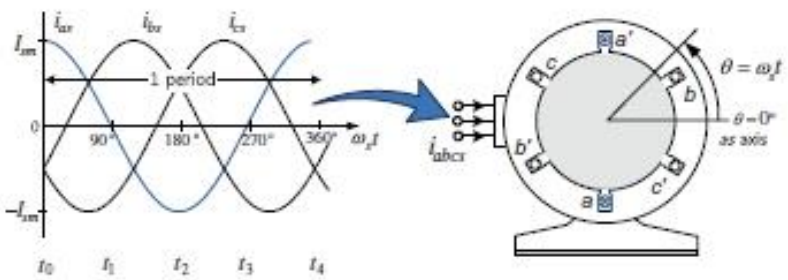

Fig. 7. Three-phase Current and Magnetic Torque [4]

Increasing the load will increase the motor coupling so that it increases the induced current in the rotor so that the slip will increase. So, when the motor load increases, the rotation of the rotor tends to decrease [7].

TABLE I. NOTATION AND DESCRIPTION OF MOTOR WORKING PRINCIPLE FORMULAS

\begin{tabular}{|c|l|}
\hline Notation & \multicolumn{1}{|c|}{ Description } \\
\hline $\mathrm{n}_{\mathrm{s}}$ & Synchronous speed $\mathrm{rpm})$ \\
\hline$f c$ & Source frequency $(\mathrm{Hz})$ \\
\hline$p$ & Number of Poles \\
\hline$e_{\text {ind }}$ & Induction Voltage (Volt) \\
\hline$v$ & The rotor speed to the rotating field speed (m/s) \\
\hline$B$ & Magnetic flux density (Tesla) \\
\hline$I$ & he length of the magnetic conductor (m) \\
\hline$T_{i n d}$ & Induction Torque (Nm) \\
\hline $\mathrm{k}$ & Torque Constant \\
\hline $\mathrm{B}_{R}$ & Rotor magnetic flux density (Tesla) \\
\hline $\mathrm{B}_{S}$ & Stator magnetic flux density (Tesla) \\
\hline
\end{tabular}

4) Direct-Quadrate Modeling

In an induction motor, there is a three-phase stator coil and a three-phase rotor coil. From here, the voltage equation will be obtained with the 6x6 matrix equation. When analyzed further, this equation will be difficult and very complex. Therefore, to simplify the analysis there is a method that will later convert the three-phase system into a two-phase system so that the voltage equation becomes a $4 \times 4$ matrix equation. This method is DQ (direct quadrate) modeling. For more details, see Figure 8 below

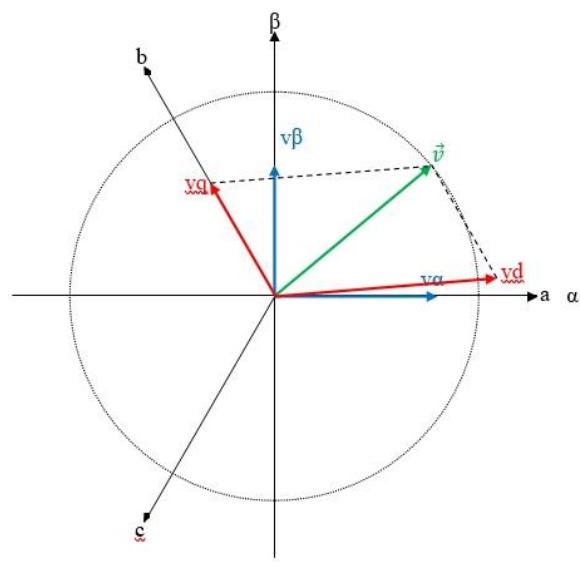

Fig. 8. Phasor diagram Induction Motor 
In a three-phase system $(\mathrm{ABC})$, the voltage resultants are obtained from the voltage resultants VA, VB, and VC. The voltage resultant turns out can be expressed in coordinates alpha-beta $(\alpha \beta)$ to be the resultant alpha voltage $(v \alpha)$ and beta voltage $(\mathrm{v} \beta)$. In this state, the three-phase system $(\mathrm{ABC})$ has been reduced to a two-phase system $(\alpha \beta)$. The resultant voltage has a fixed value and the state or phase angle changes over time. Therefore, the values of alpha $(\mathrm{v} \alpha)$ and beta $(\mathrm{v} \beta)$ voltages also vary with time as a function of sine.

The next step is to transform the alpha-beta $(\alpha \beta)$ coordinate system into the direct quadrate (DQ) system. The direct quadrate system has a two-phase system $\mathrm{d}$ and $\mathrm{q}$. The difference with the alpha-beta phase is that the voltage values $v \alpha$ and $v \beta$ change with time, such as a sine function, while the voltages $\mathrm{Vd}$ and $\mathrm{Vq}$ remain constant with time, such as direct current.

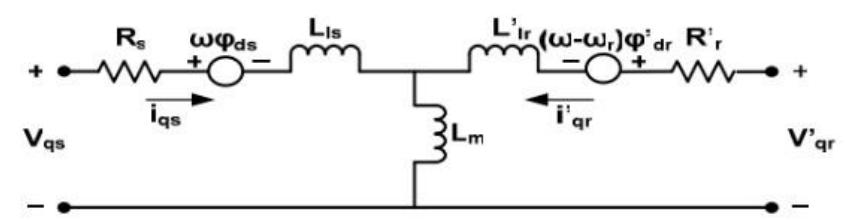

Fig. 9. Q-axis Equivalence Circuit [8]

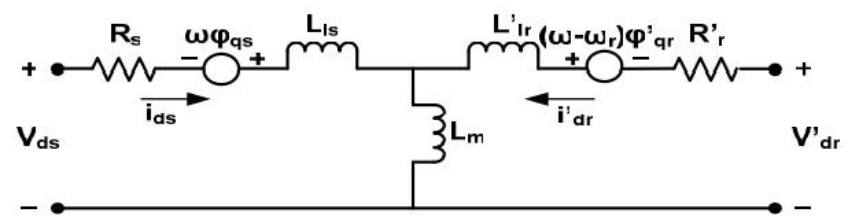

Fig. 10. D-axis Equivalence Circuit [8] axis:

The equation for the stator and rotor voltages on the DQ

$$
\begin{aligned}
& \mathrm{V}_{\mathrm{qs}}=\mathrm{R}_{\mathrm{s}} \mathrm{i}_{\mathrm{qs}}+\omega \varphi_{\mathrm{ds}}+\frac{\mathrm{d}}{\mathrm{dt}} \varphi_{\mathrm{qs}} \\
& \mathrm{V}_{\mathrm{ds}}=\mathrm{R}_{\mathrm{s}} \mathrm{i}_{\mathrm{ds}}-\omega \varphi_{\mathrm{qs}}+\frac{\mathrm{d}}{\mathrm{dt}} \varphi_{\mathrm{ds}} \\
& \mathrm{V}_{\mathrm{qr}}^{\prime}=\mathrm{R}_{\mathrm{r}^{\prime}{ }_{\mathrm{qr}}}^{\prime}+\left(\omega_{\mathrm{g}}-\omega\right)_{\mathrm{r}} \varphi_{\mathrm{dr}}^{\prime}+\frac{\mathrm{d}}{\mathrm{dt}} \varphi_{\mathrm{qr}}^{\prime}
\end{aligned}
$$

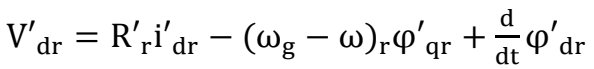

Flux equation on the DQ axis:

$$
\begin{aligned}
& \varphi_{\mathrm{qs}}=\mathrm{L}_{\mathrm{s}} \cdot \mathrm{i}_{\mathrm{qs}}+\mathrm{L}_{\mathrm{m}} \cdot \mathrm{i}_{\mathrm{qr}}^{\prime} \\
& \varphi_{\mathrm{ds}}=\mathrm{L}_{\mathrm{s}} \cdot \mathrm{i}_{\mathrm{ds}}+\mathrm{L}_{\mathrm{m}} \cdot \mathrm{i}_{\mathrm{dr}}^{\prime}
\end{aligned}
$$

with:

$$
\begin{aligned}
& \mathrm{L}_{\mathrm{s}}=\mathrm{L}_{\mathrm{ls}}+\mathrm{L}_{\mathrm{M}} \\
& \varphi_{\mathrm{qr}}^{\prime}=\mathrm{L}_{\mathrm{r}}^{\prime} \cdot \mathrm{i}_{\mathrm{qr}}^{\prime}+\mathrm{L}_{\mathrm{m}} \cdot \mathrm{i}_{\mathrm{qs}} \\
& \varphi_{\mathrm{qr}}^{\prime}=\mathrm{L}_{\mathrm{r}}^{\prime} \cdot \mathrm{i}_{\mathrm{qr}}^{\prime}+\mathrm{L}_{\mathrm{m}} \cdot \mathrm{i}_{\mathrm{qs}}
\end{aligned}
$$

with:

$\mathrm{L}_{\mathrm{r}}^{\prime}=\mathrm{L}_{\mathrm{lr}}^{\prime}+\mathrm{L}_{\mathrm{M}}$

As for the electromagnetic torque equation is:

$\mathrm{T}_{\mathrm{e}}=\frac{3}{2} \frac{\mathrm{p}}{2}\left(\varphi_{\mathrm{ds}} \mathrm{i}_{\mathrm{qs}}-\varphi_{\mathrm{qs}} \mathrm{i}_{\mathrm{ds}}\right)$

Motor speed equation :

$\frac{\mathrm{d}}{\mathrm{dt}} \omega_{\mathrm{m}}=\frac{1}{2 \mathrm{~J}}\left(\mathrm{~T}_{\mathrm{e}}-\mathrm{F} \omega_{\mathrm{m}}\right)$

$$
\frac{\mathrm{d}}{\mathrm{dt}} \theta_{\mathrm{m}}=\omega_{\mathrm{m}}
$$

The voltage equation on the DQ axis using the phase-toneutral voltage can be written as follows:

$\left[\begin{array}{c}\mathrm{V}_{\mathrm{qs}} \\ \mathrm{V}_{\mathrm{ds}}\end{array}\right]=\frac{1}{3}$

$\left[\begin{array}{lll}2 \cos \theta & (-\cos \theta+\sqrt{3} \sin \theta) & -(\cos \theta+\sqrt{3} \sin \theta) \\ 2 \sin \theta & -(\sin \theta+\sqrt{3} \cos \theta) & (-\sin \theta+\sqrt{3} \cos \theta)\end{array}\right]$

$\left[\begin{array}{c}\mathrm{V}_{\mathrm{as}} \\ \mathrm{V}_{\mathrm{bs}} \\ \mathrm{V}_{\mathrm{cs}}\end{array}\right]$

$\left[\begin{array}{c}\mathrm{V}^{\prime} \\ \mathrm{qr}^{\prime} \\ \mathrm{dr}_{\mathrm{dr}}\end{array}\right]=\frac{1}{3}$

$\left[\begin{array}{lll}2 \cos \beta & (-\cos \beta+\sqrt{3} \sin \beta) & -(\cos \beta+\sqrt{3} \sin \beta) \\ 2 \sin \beta & -(\sin \beta+\sqrt{3} \cos \beta) & (-\sin \beta+\sqrt{3} \cos \beta)\end{array}\right]$
$\left[\begin{array}{l}\mathrm{V}^{\prime}{ }_{\mathrm{ar}} \\ \mathrm{V}^{\prime}{ }_{\mathrm{br}} \\ \mathrm{V}^{\prime}{ }_{\mathrm{cr}}\end{array}\right]$

As for the current equation [8]:

$$
\begin{aligned}
& {\left[\begin{array}{l}
\mathrm{i}_{\mathrm{as}} \\
\mathrm{i}_{\mathrm{bs}}
\end{array}\right]=\left[\begin{array}{cc}
\cos \theta & \sin \theta \\
\frac{-\cos \theta+\sqrt{3} \sin \theta}{2} & \frac{-\sqrt{3} \cos \theta-\sin \theta}{2}
\end{array}\right]\left[\begin{array}{l}
\mathrm{i}_{\mathrm{qs}} \\
\mathrm{i}_{\mathrm{ds}}
\end{array}\right]} \\
& {\left[\begin{array}{l}
\mathrm{i}^{\prime}{ } \\
\mathrm{i}^{\prime}{ }_{\mathrm{br}}
\end{array}\right]=\left[\begin{array}{cc}
\cos \beta & \sin \beta \\
\frac{-\cos \beta+\sqrt{3} \sin \beta}{2} & \frac{-\sqrt{3} \cos \beta-\sin \beta}{2}
\end{array}\right]\left[\begin{array}{l}
\mathrm{i}_{\mathrm{qs}} \\
\mathrm{i}_{\mathrm{ds}}
\end{array}\right]} \\
& \mathrm{i}_{\mathrm{as}}+\mathrm{i}_{\mathrm{bs}}+\mathrm{i}_{\mathrm{cs}}=0 \\
& \mathrm{i}_{\text {ar }}^{\prime}+\mathrm{i}_{\text {br }}^{\prime}+\mathrm{i}_{\text {cr }}^{\prime}=0
\end{aligned}
$$

\section{5) Finite Element Method (FEM)}

The finite Element Method is a numerical method that can be used to solve integral equations and differential equations. This method is often used to solve electromagnetic problems so that it can be used to solve induction motor problems.

The basic concept of FEM is to solve problems by dividing objects into a mesh (collection of elements) into finitely small parts. These small parts will be analysed according to the problem and the results will be collected back to solve the equation. The types of problems to be solved using the FEM method are divided into two, namely structural analysis and non-structural analysis. In the induction motor, the analysis used is the non-structural analyst. This analysis is used to analyse the potential of the magnetic field and the electric field.

\section{B. Construction Design}

The first thing to pay attention to when designing a motor construction is what size the machine will be made, including the size of the stator, the size of the rotor, the air gap, and so on. These parameters will affect the performance of the motor. The size of the motorbike will be adjusted to the standard size of the car drum of $228.6 \mathrm{~mm}$. For the voltage source, a 72-volt battery will be used. We are going to use the Altair Fluxmotor application to design and simulate. The following is a table of parameters and their assumed values. 


\begin{tabular}{|l|l|}
\hline \multicolumn{1}{|c|}{ Description } & \multicolumn{1}{c|}{ Value } \\
\hline Motor length & $80 \mathrm{~mm}$ \\
\hline Stator inner diameter & $80 \mathrm{~mm}$ \\
\hline Stator outer diameter & $182,6 \mathrm{~mm}$ \\
\hline Rotor inner diameter & $183,6 \mathrm{~mm}$ \\
\hline Rotor outer diameter & $218,6 \mathrm{~mm}$ \\
\hline Housing diameter & $228,6 \mathrm{~mm}$ \\
\hline Cable diameter & $2 \mathrm{~mm}$ \\
\hline Cable isolation thickness & $0,05 \mathrm{~mm}$ \\
\hline Prespan thickness & $0,12 \mathrm{~mm}$ \\
\hline
\end{tabular}

The above parameters have been met and can be used as electric car propulsion. The inner diameter of the stator measuring $80 \mathrm{~mm}$ is suitable as a wheel axle. Because the car tire is supported only on one side, the size of the axle is large. $80 \mathrm{~mm}$ size is already widely available in cars in circulation. for the size of the rotor, the thinner the rotor, the farther from the motor center, the higher the torque generated but the less flux from the induced rotating field in the rotor. The number of slots on the rotor and stator must be a multiple of the number of poles.

The size of the air gap is $0.5 \mathrm{~mm}$ which is already small. The length of the magnetic circuit is also the length of the motor. The motor length of $80 \mathrm{~mm}$ can be used to drive the car inside the wheels. The cable diameter is $2 \mathrm{~mm}$ because if it is smaller than the maximum current it accommodates will also decrease and if it is bigger than when rolled up it can break the insulation of the cable. For other parameter sizes, it will be stated both based on simulation and analysis as well as specifications on existing electric cars.

The type of rotor used is the NEMA design class D. This type of rotor has a small and short rotor shaft construction. The type $\mathrm{D}$ rotor has the highest starting torque required for electric car use [9]. The following is the picture for the type D rotor

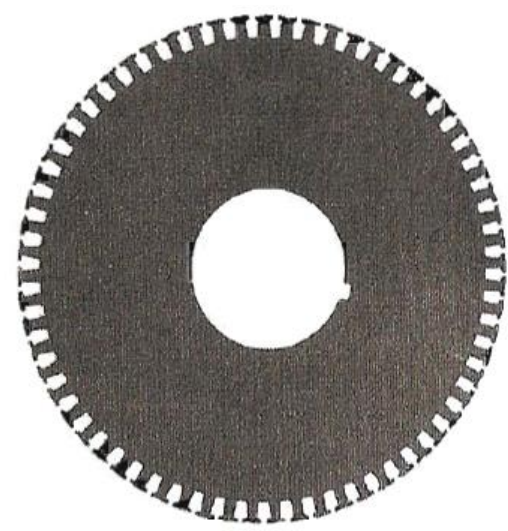

Fig. 11. NEMA design class D Rotor.[5]

At the time of the simulation, it should be noted that the current limit that can be passed on the stator coil is $22 \mathrm{~A}$. The value of the source frequency is adjusted to a speed of $25 \mathrm{~km} /$ $\mathrm{h}$ as a benchmark so that at the time of simulation 32 poles the source frequency is $62 \mathrm{~Hz}$ when 16 poles the source frequency is $31 \mathrm{~Hz}$ when 8 poles the source frequency is $15.5 \mathrm{~Hz}$ when 4 poles the source frequency is $7.75 \mathrm{~Hz}$, and, when 2 poles the source frequency is $3.875 \mathrm{~Hz}$.

Design parameters for outer rotor type design Induction motors consider many things such as the number of stator/rotor slots, the shape of the stator and rotor slots, winding that can determine the amount of output, efficiency, torque [10].

\section{RESULTS AND DISCUSSION}

After a series of simulations were carried out, a final design was obtained which was the best design that could be applied to an electric car. The size of the motor engine parameters in the final design is following the previous table 1 . The following are the final design parameters obtained from a series of simulations.

TABLE III. FinAl Design PARAmeter VAlues

\begin{tabular}{|l|l|}
\hline \multicolumn{1}{|c|}{ Description } & \multicolumn{1}{c|}{ Value } \\
\hline Number of poles & 8 \\
\hline Number of coils & 16 \\
\hline Number of stator slot & 96 \\
\hline Number of rotor slot & 96 \\
\hline Air gap & $0,5 \mathrm{~mm}$ \\
\hline Stator slot length & $35 \mathrm{~mm}$ \\
\hline Rotor slot diameter & $3.8 \mathrm{~mm}$ \\
\hline
\end{tabular}

With using the final design parameters, we will see the response for speed $25 \mathrm{~km} / \mathrm{h}, 50 \mathrm{~km} / \mathrm{h}, 75 \mathrm{~km} / \mathrm{h}$, and $100 \mathrm{~km} / \mathrm{h}$.

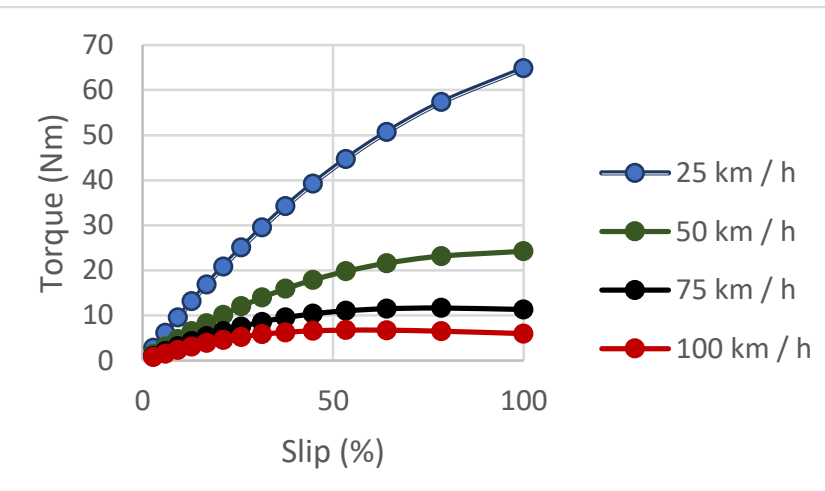

Fig. 12. Torque Response Each Speed Limit

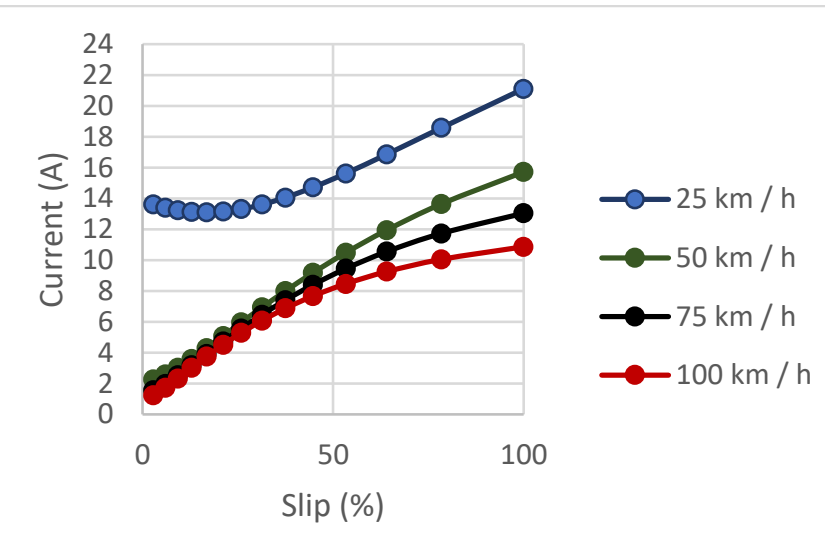

Fig. 13. Current Response Each Speed Limit 


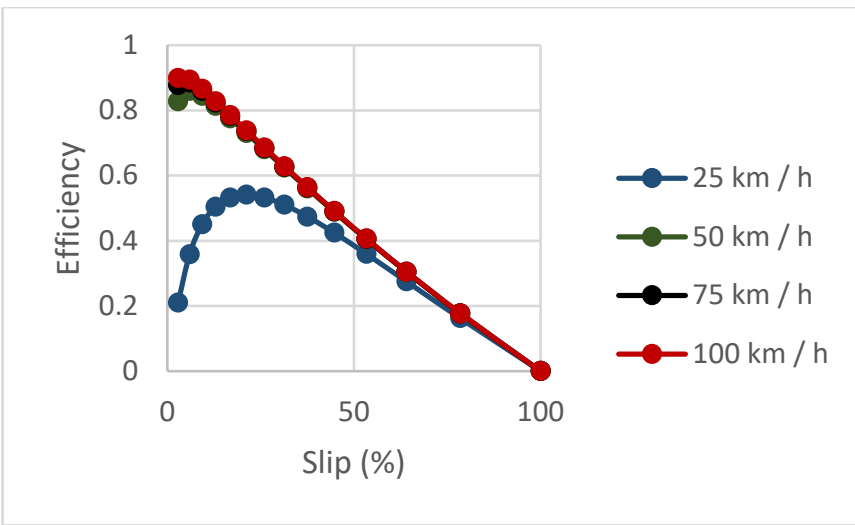

Fig. 14. Efficiency Response Each Speed Limit

If the speed limit is low, the given source frequency is also low so that the current and torque are higher, but the efficiency tends to be lower. Likewise, if the speed limit is high, the current and torque are lower, and the efficiency tends to be higher. With a torque obtained of $64 \mathrm{Nm}$, after calculating, the incline angle that can be traversed in $11.59^{\circ}$

The comparison of the result at $25 \mathrm{~km} / \mathrm{hr}$ with the fem method and modelling are shown in picture below

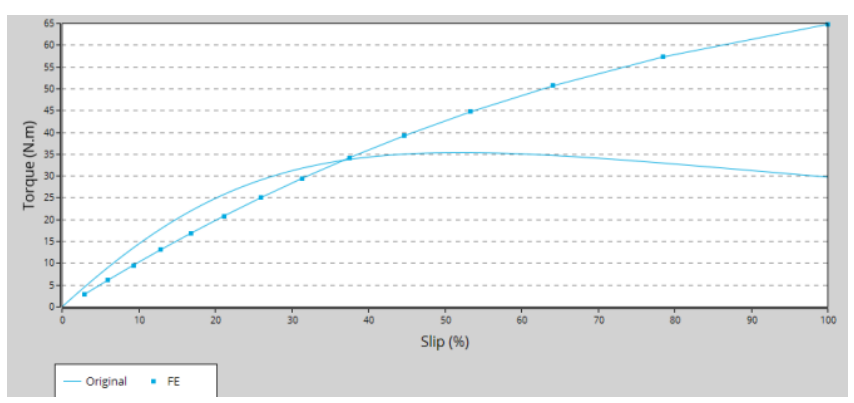

Fig. 15. Torque Comparison of FEM Method and Modeling

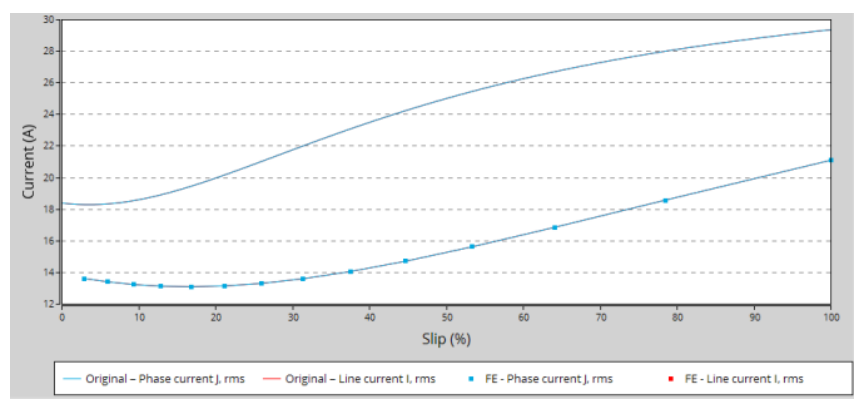

Fig. 16. Electrical Current Comparison FEM Method and Modeling

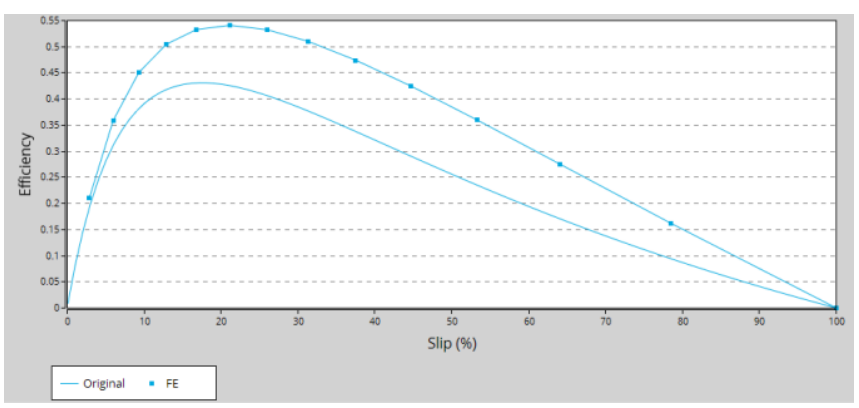

Fig. 17. Efficiency Comparison FE, Method and Modeling

The value obtained from the FEM method is more accurate and close to the original because the modeling method does not take into account the distribution of the magnetic field from the smallest part of the rotor and stator. The stator and rotor parts are considered homogeneous. The modeling method also does not take into account the hysteresis factor so that the FEM method is more accurate than the modelling method.

\section{CONCLUSIONS}

In determining the parameters, some ways can be done to increase the torque which will increase the current and decrease the efficiency as well as decrease the current which simultaneously decreases the torque and increases the efficiency. One way is to adjust the number of turns on the coil and the cable diameter. Reducing the number of turns and increasing the diameter of the cable will make the cable shorter. As a result, the resistance decreases, and the current increases. The increase in current results in an increase in torque as well as increases in power losses which results in decreased efficiency. Likewise, increasing the number of turns and reducing the diameter of the cable will make the resistance increase, and the current decreases. The decrease in current causes the torque value to decrease and the power losses decrease so that efficiency increases.

The best design has the number of poles as many as 8 with the number of stator/rotor slots of 96/96. This makes sense because if there are too many poles, the distance between the same poles will be close together so that it cancels outflux and if it is too small then the stator cavities at one pole can cancel each other out because the distance can cause the flux to overlap. After all, it is in opposite directions.

\section{REFERENCES}

[1] Bagia, N. I. Parsa, M. I., "Motor-Motor Listrik", New Delhi: CV Rasi Terbit, 2018

[2] Theraja, B. L. Theraja, A.K., "A Text Book of Electrical Technology: Volume II", New Delhi: S. Chand and Company, 1995.

[3] Ghazaly, R. A., "Metode Perhitungan Motor Induksi yang Sedang Beroperasi”, Skripsi, Universitas Indonesia, Depok, 2011.

[4] Kim, S. H., "Electric Motor Control", Elsevier, 2017.

[5] Chapman, S. J., "Electric Machinery Fundamentals: Fifth Edition", McGraw-Hill.Inc, 2012.

[6] Hughes, A., "Electric Motors and Drives: Third Edition", Elsevier Ltd, 2012.

[7] Zuhal, "Dasar Tenaga Listrik dan Elektronika Daya", PT Gramedia Pustaka Utama, Jakarta, 2000.

[8] Jie, S., "Pemodelan dan Pengendalian Kecepatan Motor Induksi Tiga Fasa", Program Pasca Sarjana, Universitas Hasanuddin, Makassar, 2009.

[9] Rabbani, I., "Deteksi Kerusakan Batang Rotor Pada Motor Induksi Tiga-Fasa Menggunakan Analisis Bi-Spectrum”, Tugas Akhir, Institut Teknologi Sepuluh Nopember, Surabaya, 2016.

[10] Cha, H. R.; Jeong, W. T. B.; Won, Im, Y. D.; Shin, J. K.; Seo, J. Y., "Design of Outer Rotor type Induction Motor Having High Power Density for In-Wheel System", Automotive Components Research Group, Honam Regional Division, Korea Institute of Industrial Technology; Suncheon First College, Department of Electrical Control; SRC Ltd. Co. Dep. Of Technical Research Center, Korea. 